\title{
Comparison of Binding and Interaction Studies of Metal lons/Surfactant with Protein by Various Physical Methods
}

\author{
Shveta Acharya and Arun Kumar Sharma*† \\ Department of Chemistry, Govt. College, Kota-324010, Rajasthan, India \\ *Department of Chemistry, Govt. P.G. College, Jhalawar-326001, Rajasthan, India \\ $†$ Corresponding author: Arun Kumar Sharma; sharmaarun423@gmail.com
}

Nat. Env. \& Poll. Tech.

Website: www.neptjournal.com

Received: 21-07-2019

Accepted: 29-08-2019

Key Words:

Surfactants; Metal ions;

Albumin; Viscosity;

Diffusion current;

Egg-protein; Scatchard

plots; Equilibrium dialysis

\begin{abstract}
The metal ions play a vital role in a large number of widely differing biological processes. Some of these processes are quite specific in their metal ion requirements. In that only certain metal ions, in specific oxidation states, can fulfil the necessary catalytic or structural requirement, while other processes are much less specific. In this paper, the interactions between triethanolamine, lauryl sulphate and albumin molecules have been reported. The $\mathrm{pH}$ and diffusion current measurements on the binding of copper and mercury ions with albumin have been discussed. The effect of physico-chemical factors on the interaction between divalent metal ions and albumin has been carried out. Physico-chemical studies on the binding of $\mathrm{Hg}(\mathrm{II})$ and $\mathrm{Cu}$ (II) with albumin have been discussed.
\end{abstract}

\section{INTRODUCTION}

The term biopolymer includes a variety of macromolecules including proteins, carbohydrates, nucleic acids, etc., for example, proteins are widely distributed in cells of plants, vertebrates, invertebrates, and microorganisms. They have a variety of functions. The fertilizine, a protein, present at the surface of ova is responsible for reproduction. Some of them act as hormones, enzymes and as inhibitors. In almost every field of biology, biopolymers find remarkable applications. The uses of these proteins as lubricants, carriers, and structural proteins, etc. are well known (Arora et al. 1983a).

The interactions between acidic and basic macromolecules in the living systems in the presence of micromolecule ions form the basis of the formation of biofluids and these combinations have been included under the trophic phase equilibria in systems of interacting polyelectrolytes. It has been assumed that the coacervation mixing process represents the primary ordering process by which mixtures of randomly formed pre biologic polymers were condensed into preprotoplasmic assemblies. Such studies on complex coacervation have thrown light on the development of living systems via interactions between the random polymers produced in the atmosphere of the earth (Harris 1984). The interactions between proteins and a variety of bio-acceptable compound/ion have been carried out for several reasons. The most significant of these is to find out the effect of any particular compound for any specific system among the various bioactive compounds. The metal ions play a vital role in a large number of widely differing biological processes. Some of these processes are quite specific in their metal ion requirements. In that only certain metal ions, in specific oxidation states, can fulfil the necessary catalytic or structural requirement, while other processes are much less specific. It is possible to replace one metal ion by another, although the activity may be reduced. Metals like $\mathrm{Mg}, \mathrm{Mn}, \mathrm{Fe}, \mathrm{Co}, \mathrm{Cu}, \mathrm{Mo}$ and $\mathrm{Zn}$ are important catalysts of a variety of enzyme reactions such as group transfer, redox or hydrolytic processes. Some protein system is involved in strong and controlling the concentration of the metal ion and then in transporting it to the appropriate sites of the enzyme (Dudev et al. 2003). Many of them are used in maintaining the structure and controlling the function of the cell wall. Not only the common metals but even the lanthanide that finds usage as a nuclear magnetic resonance shift probe in biological systems. The physiological $\mathrm{pH}$ is limited to 7.0-7.5 while these lanthanide ions are reported not to be precipitated even up to $\mathrm{pH} 8.43$, thus it is feasible to say that in this sense they are even superior then 
the well-known biologically active ferric and chromic ions (Harding 2004). These ions are reported to form complexes with adenosine monophosphate. The role of uranyl ions in enzymatic systems has recently been reported by several workers (Acharya \& Sharma 2018a).

\section{MATERIALS AND METHODS}

\section{Characterization of Metal Protein Complex}

Many complexities arise in the investigation of proteins, which are ascribed to factors like uncertainty in molecular weights and variation in chemical behaviour depending on the nature, origin, purity and their great sensitivity to denaturation. A large number of physico-chemical methods, viz. ultracentrifugation, ultrafiltration, magnetic susceptibility, light scattering solubility, precipitation, migration in electric field polarography, spectrophotometry, equilibrium dialysis, electrophoretic mobility, $\mathrm{pH}$ displacements, electron paramagenetic resonance (EPR), optical rotatory dispersion (ORD), circular dichroism (CD), Mossbauer spectroscopy, etc. have been used in ascertaining the mode of binding and also in achieving greater success in quantitative aspects of metal protein problem. Besides these techniques, the chemical testing of metalloenzyme and aproenzyme for the presence of specific groups has been of great value (Lu et al. 2008).

\section{Detergent-Protein Interaction}

The interaction of synthetic detergents to proteins has been studied for several reasons. Depending on the nature of the protein, association or dissociation complexation, denaturation, precipitation, etc. may occur. These have also been used to expose groups in proteins normally unavailable to specific reagents. In many cases, they are used for isolation of protein. SDS has also been used for the extraction of transforming DNA. Several workers have also shown protein precipitated by anionic detergent does not show any change in its viscosity after its recovery from the detergent protein complex (Frassinetti et al. 2006). Among anionic detergents used, the interaction of SDS with proteins, besides including anti-parallel sheet conformation. The survey of the existing literature revealed that the binding of molybdenum, vanadium, zinc, cadmium, copper, nickel and cobalt is lacking to egg albumin, similarly, no binding studies of molybdenum copper and mercury are made with nucleic acid and those of anionic surfactants with albumin (Keilin \& Mann 1940). Investigations on the aspects of these binding problems were planned and their binding constants have been determined using suitable physico-chemical methods (Zheng et al. 2008).

\section{pH Measurement}

These were carried out with a digital Systronics $\mathrm{pH}$ meter using a wide range glass electrode. The instrument was calibrated against $0.05 \mathrm{M}$ potassium hydrogen phthalate ( $\mathrm{pH} 4.0$ ) and $0.05 \mathrm{M}$ sodium borate $(\mathrm{pH} 9.20)$ for acidic and alkaline ranges, respectively.

\section{Diffusion Current Measurements}

These measurements were carried out on a Toshniwal polarograph Model $\mathrm{Cl}$ 02A in conjunction with an Osaw galvanometer in the external circuit. An H-shaped polarographic cell as recommended by Tanford was used. Nitrogen, purified by passing through a solution of chromous chloride and alkaline pyrogallol, was passed through the solution for producing an inert atmosphere. Triply distilled mercury was used for the D.M.E. The cell was immersed in water thermostat maintained at $25 \pm 0.1^{\circ} \mathrm{C}$. The capillary used had a flow rate of about $2.2 \mathrm{mg} / \mathrm{s}$ with a drop time of $3.5 \mathrm{~s}$. Since the capillary characteristics $(m, t)$ have a marked effect on diffusion current, which is directly proportional to $\left(\mathrm{m}^{2 / 3}, t^{1 / 6}\right)$, these factors were therefore controlled carefully throughout these experiments (Acharya \& Sharma 2018b).

\section{RESULTS AND DISCUSSION}

\section{Binding Sites of Surfactant with Albumin}

In the binding of anionic surfactant to albumin, it has been observed that in each case of the mode of combination of the triethanolamine lauryl sulphate (TEALS) ions to albumin, change in three distinct patterns of the free concentrations of surfactant is progressively raised. The patterns of linking have been roughly demarcated by dividing the logarithmic plots into three areas A, B and C to understand the mechanism of TEALS albumin combination at different stages (Fig. 1). In going from acetylated albumin, formylated albumin to esterified albumin the region 'A' goes on lengthening in area followed by vanishing the vertical shape. Similarly, the logarithmic plots, in case of albumin at varying temperatures, indicated a nature like those of protein derivatives i.e. resin 'A' increasing, B decreasing and ' $C$ ' assuming vertical, identifying with the raising temperature. The variation in the pattern of the length of different zones is indicative of the elimination of some intermediates is surfactant albumin interaction, thus the effect of temperature on binding isotherms appears to follow the same course so the protein charge. Further, the relative position and highly vertical shape of the isotherms in case of higher temperature and esterified protein indicates some structural changes in surfactant and protein or both proportion of albumin to surfactant. The plot or $\Upsilon$ vs 
$\log$ free surfactant concentration followed a linear course. The linearity of plots is in favour of more or less statistical distribution as the surfactant on the entire available albumin molecule in this region. The binding data in the statistical region were determined by the application of Scatchard equation in the form (Lyons et al. 2006):

$$
\Upsilon / D_{F}=K_{n}-K_{r}
$$

$\Upsilon$ and $D_{F}$ have their usual meaning and $K$ is the average apparent association constant for binding at each site and $\mathrm{n}$ is the average maximal number of binding sites on macromolecule with the same association constant $\mathrm{K}$. The effect of temperature is highly interesting as is evident from the values of $n$ and $K$. The hyperbolic character of plots increases with rising temperatures. The linearity of region ' $\mathrm{A}$ ' continues to increase, region ' $\mathrm{B}$ ' decreasing and the nature of region ' $\mathrm{C}$ ' becoming more and more vertical with $\Upsilon / D_{F}$ axis. The elevated temperature thus vanishes the transition state of unfolding in region ' $\mathrm{B}$ ' and causes its rapid unfolding as shown by the plots in region ' $\mathrm{C}$ '. The increasing values of binding sites(n) in the statistical region and increasing values of surfactant moles bound per mole of albumin $(\Upsilon)$ in region ' $C$ ' suggest that conformational variations in the albumin molecule exposed more and more positive and apolar groups for linkage with the TEALS ions (Acharya \& Sharma 2018c).

\section{Thermodynamic Studies}

The intrinsic constant $(\log \mathrm{K})$ at all the reaction temperature appears to be almost the same. This is indicative of a single

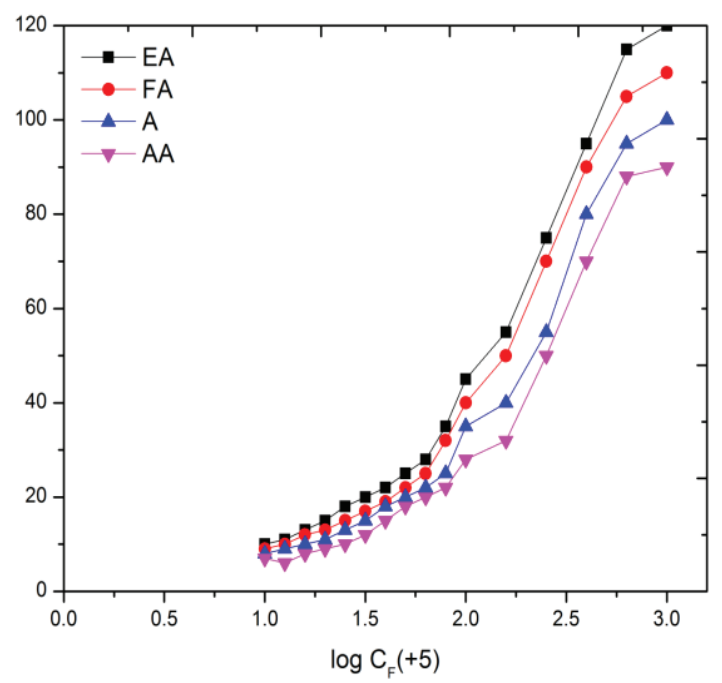

Fig. 1: Logarithmic plots for TEALS albumin and its derivatives at $\mathrm{pH}=7.40$ type of site reacting with the TEALS molecule in the statistical zone. The occurrence of the different number of sites (n) is therefore not responsible for enhanced linkage, which is probably due to the increased availability of the same type of sites. The increasing value of $\mathrm{n}$ as the temperature rises at $\mathrm{pH} 7.40$ is indicative of this. The thermodynamic constant viz. free energy $\left(\Delta \mathrm{G}^{\circ}\right)$ enthalpy $\left(\Delta \mathrm{H}^{\circ}\right)$ and entropy $\left(\Delta \mathrm{S}^{\circ}\right)$ also revealed the uniformity of $\log \mathrm{K}$ and the involvement of a single type of site in TEALS - albumin combination. The free linkage energy is mostly due to changes in entropy, the apparent enthalpy contribution being small and sometimes close to zero. The entropy changes are in the range of 7.8 to $1.9 \mathrm{cal} / \mathrm{mole}$ within which the entropy values of the TEALS albumin reaction lie (Harding 1999).

From the data as unmodified and modified proteins, one can see the difference in the ionic and hydrophobic linkage of the straight-line region (A) decrease from EA, A, FA and AA as well as the following sequence $E A>A>F A>A A$. (Fig. 2) This indicates that the larger the positive charge, the greater is the surfactant linkage. The higher linkage with EA is because there is no electrostatic repulsion between surfactant anions and the protein because extension protected the carboxyl groups so that the negative charge which effected the surfactant linkage line region (Tank et al. 2018). On the other hand, formylation extracts albumin positive charge, thereby resulting in a decreased surfactant linkage. However, in the higher linkage, in all cases the nature of linkage remained unaffected, hence these linking parameters show that hydrophobic linkage is much more significant in surfactant-protein linking (Joshi 2018).

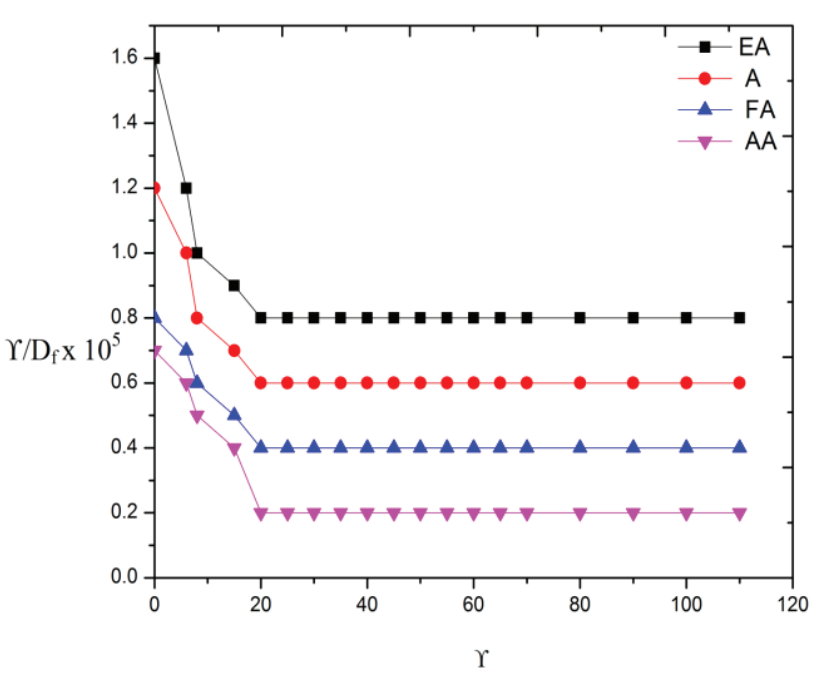

Fig. 2: Scatchard plots of albumin and its derivative for the linkage of TEALS at $\mathrm{pH}=7.4, \mathrm{~T}=25^{\circ} \mathrm{C}$ 


\section{pH Metric Studies}

The $\mathrm{pH}$ titration of 0.05 percent albumin in the absence and presence of $2.0 \times 10^{-3} \mathrm{~m} \mathrm{Hg}^{++}$and $\mathrm{Cu}^{++}$ions has also been observed (Fig. 3). The titration curve of albumin alone lies above the similar curve of mercury-albumin mixtures throughout the whole $\mathrm{pH}$ range. The decrease in $\mathrm{pH}$ by the addition of albumin to mercury ion solution indicates that hydrogen is displaced by mercury ions from reactive sites of albumin. This shift of titration curve towards a more acidic side of the functional groups is indicative of an interaction between mercury ions and the albumin. The $\mathrm{pH}$ titration of copper is analogous with the mercury curve. The $\mathrm{pH}$ displacements are larger in copper-albumin than in mercury-albumin (Kumar et al. 2018).

The polarographic measurements on the mercury-albumin system revealed that the presence of increasing amounts of albumin decreased the diffusion current of mercury ions. Assuming that the decrease in diffusion current in metal ion is solely due to complex formation between metal and protein. The mercury and copper ions also give a reversible polarogram. The strength of the respective linkage may be compared by knowledge of formation constants and thermodynamic parameters. The formation constant ( $\log \mathrm{K})$ for mercury-albumin was computed from classical Scatchard's equation. These were found out to be 1.16, 2.69 and 3.38 for mercury-carboxyl, mercury-imidazole and mercury-amino linkage respectively, the free energy change for the different linkages were found to be $1.619,3.755$ and $4.718 \mathrm{Kcal} / \mathrm{mole}$. The comparison of $\log \mathrm{K}$ and free energy values of different linkage justified a stronger combination with amino groups and weakest for carboxyl groups (Kumar et al. 2018).
The addition of albumin to mercury ions solution caused a decrease in its current height, which continuously decreased with increasing concentration of protein and finally become more or less constant. This decrease in the current height could not be due to viscosity changes and absorption on the mercury drops since the studies were made in a higher $\mathrm{pH}$ range. The result of the mercury-albumin system may be explained as similar to that of copper-albumin (Hawker et al. 2018).

\section{Diffusion Current Result}

The diffusion current of 0.833 molar buffered copper sulphate solution was depressed by the addition of 0.5 percent albumin. This depression was continuous by increasing the albumin concentration and it ultimately becomes constant at an extremely higher concentration of albumin in a similar way. When 0.1 percent albumin was added to varying amounts of copper solution the diffusion current was depressed in proportions of the copper ion solution (Sharma et al. 2018). The linking result can be calculated by taking diffusion current ratio of metal alone and when albumin is present in the mixtures.

For the study of $\mathrm{pH}$ displacement from ligand by the added metal cations albumin (A) alone and in the presence of $2.0 \times 10.3 \mathrm{M}$ cobalt chloride, nickel chloride and manganese chloride, it was titrated against $0.10 \mathrm{M}$ hydrochloric acid and $0.10 \mathrm{M}$ potassium hydroxide, respectively. Nickel and manganese did not show any binding with the carboxyl groups from the nature of titration curves. It is because the drifts of titration curves above protein are indicative of the adsorption of hydrogen ions (Stern et al. 2007). It appears that these metal ions formed insoluble complexes with

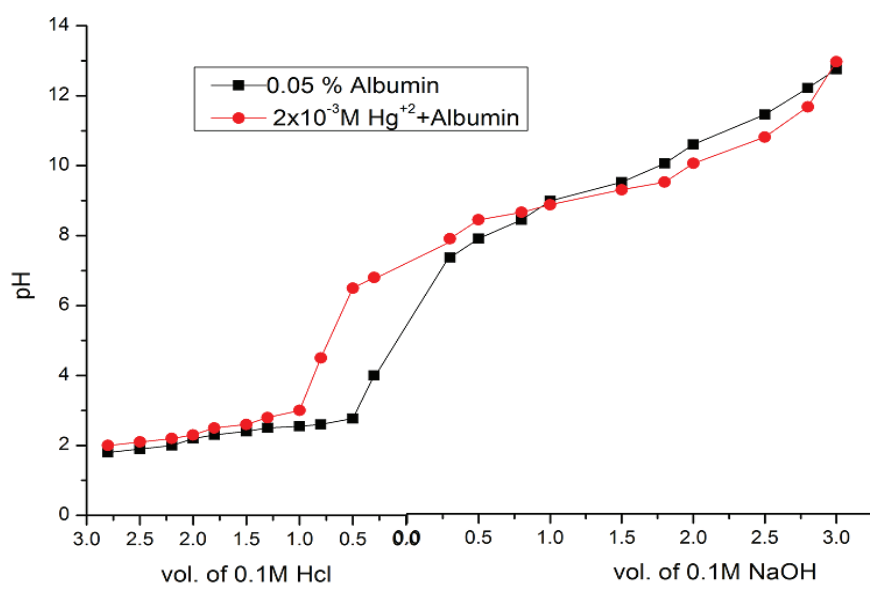

Fig. 3: Titration curve of albumin in the absence and presence of mercury ions. 
albumin in lower $\mathrm{pH}$ range and the precipitate adsorbs the added hydrogen ions (Stewart et al. 2003). However, in the alkaline range, both nickel and manganese displaced protons from imidazole and ammonium groups of albumins. This cobalt-manganese and nickel ions get co-ordinated with nitrogen atoms with histidyl and lysyl amino acid residues as protein (Harding 2000).

\section{Transmittance Measurements}

The absorption spectra of nickel and manganese show maxima at 675 and $775 \mathrm{~nm}$ respectively (Fig. 4). The presence of 0.15 to 0.08 percent albumin does not alter the position of maxima, but the absorbance of nickel-albumin mixture is increased. This increase in the absence of the addition of albumin is an indication of interaction between $\mathrm{Ni}(\mathrm{II})$ and reactive groups on albumin molecule (Acharya \& Sharma 2018d). However, the addition of 0.75 to 1.5 percent albumin at $\mathrm{pH} 5.0$ caused a shift in maxima i.e. it changed from 675 to 600 . Such a characteristic shift is due to the chelation of nickel ions with carboxyl groups as protein. The increase in the absorbance by the addition of albumin provides enough qualitative evidence for the linking of cobalt ions by the protein. The addition of gradually increasing amounts of the protein brings about a much marked increase in absorbance so that in the presence of 1.8 percent albumin, the absorbance increases from 0.012 to 0.024 . The fact was further supported by the results on mixtures having a fixed amount of albumin and cobalt chloride at different $\mathrm{pH}$ values when the absorbance was found in increasing order, since in the $\mathrm{pH}$ range 3.25 to 5.30 the carboxylic groups lose their protons. Hence, due to rising $\mathrm{pH}$ more carboxylic groups lose their protons and more carboxyl become ionised for linking with the cobalt ions (Drabovich et al. 2013).

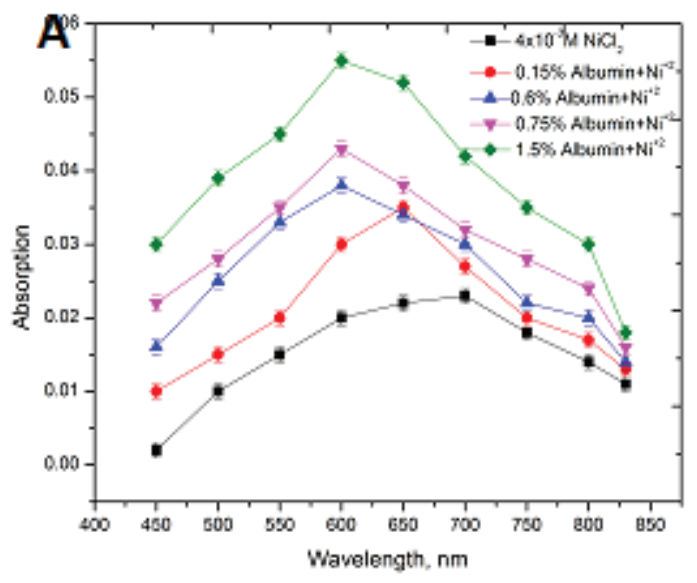

The metal oxide colloidal micelles are positively charged and therefore combination with anionic albumin may be affected either through mutual adsorption or through purely chemical forces where the metal ions form the inner part of the double layer, make themselves available for reaction with the reactive sites of the albumin molecule. The titration curves of albumin metal oxide solution lie above the corresponding curves of the solution and for $\mathrm{KOH}$ in all the cases, binding occurred above $\mathrm{pH} 10.50$ where all the carboxyl and phenolic groups are anionic while the imidazole and amino groups are fully deprotonated. The extent with which solution alkali or electrolyte may be assumed as a qualitative measure of the extent of metal albumin linking. In general, the complexes are formed through chelation to carboxyl and co-ordination with the nitrogen of imidazole and amino groups of albumins (Van 2013).

\section{Viscometric Results}

The viscosity data on the binding also favoured interaction of anionic albumin with metal oxide solution. The progressive addition of metal oxide solution to a fixed amount of albumin caused regularly increased viscosity, providing valuable information about the mutual interaction of hydrophobic and hydrophilic solution. From viscosity solution concentration curves, it is evident that a sharp inflexion occurred in each curve which represented a new slate of aggregation in the colloidal system. It might be concluded that it was due to the formation of absolutely positive charge complexes (Fig. 5) (Acharya \& Sharma 2019a-c).

In the case of pH-metry, no binding of nickel ions is indicated with carboxyl groups, while spectrophotometry showed the linking of nickel ions with carboxylate residues

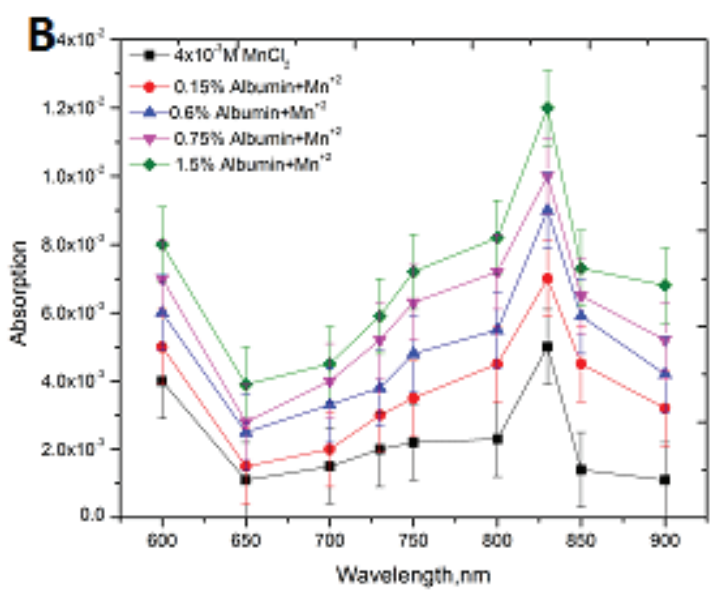

Fig. 4: Absorption spectra $4 \times 10^{-3} \mathrm{M} \mathrm{Ni}^{+2}$ (A) $\mathrm{Mn}^{+2}$ (B), at different amounts of albumin at $\mathrm{pH}=5.0$. 
of albumin. The $\mathrm{pH}$ metric as well as viscometric data provided sufficient evidence about the linking of cobalt, nickel and manganese ions with the nitrogen groups of albumins. From the nature and height of curves in the three cases, it may be concluded that nickel ions bound strongly (Fig. 6), while the cobalt ions bound weakly in $10.0 \mathrm{~mL}, 0.3$ percent albumin solution of different $\mathrm{pH}$ as the protein (Espósito $\&$ Najjar 2002). The $\mathrm{pH}$ values of the above mixtures were recorded immediately after mixing and after 24 hours. These measurements at $\mathrm{pH} 5.35,9.85$ and 11.50 were carried out at $25^{\circ} \mathrm{C}$ and $40^{\circ} \mathrm{C}$ respectively.

In the study of binding $\mathrm{Cu}$ ions to albumin was calculated by carrying out direct and reserve titrations. The inflexion in the transmittance versus concentration curves indicates the point where the formation of the insoluble complex is incomplete. Furthermore, if this point does not indicate the completion of the formation of the insoluble complex, then with the addition of more $\mathrm{Cu}$ would be an even larger

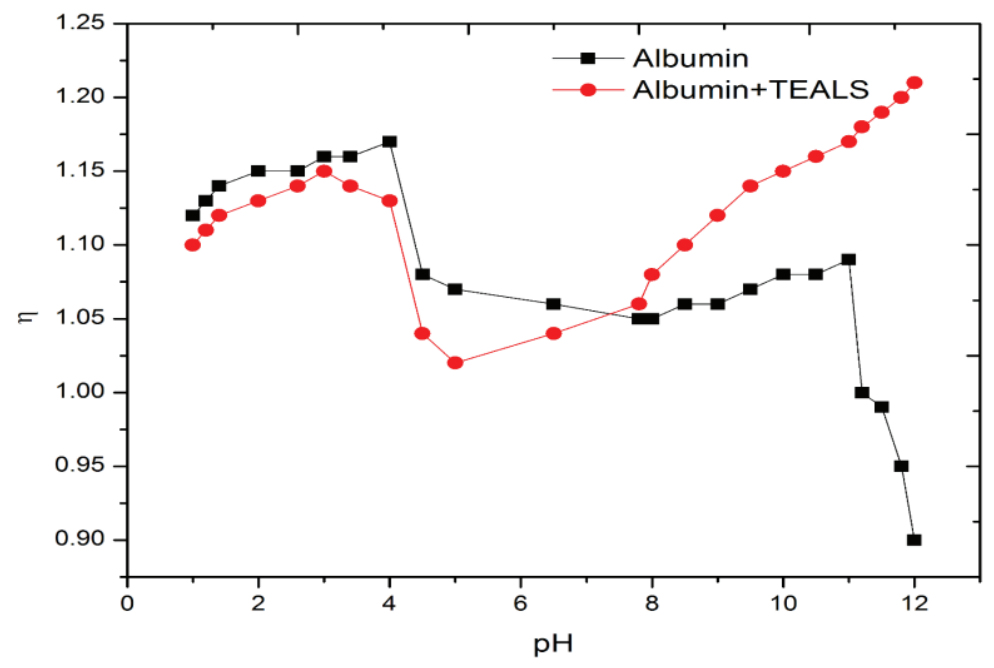

Fig. 5: Relative viscosity v/s pH plots for albumin TEALS system.

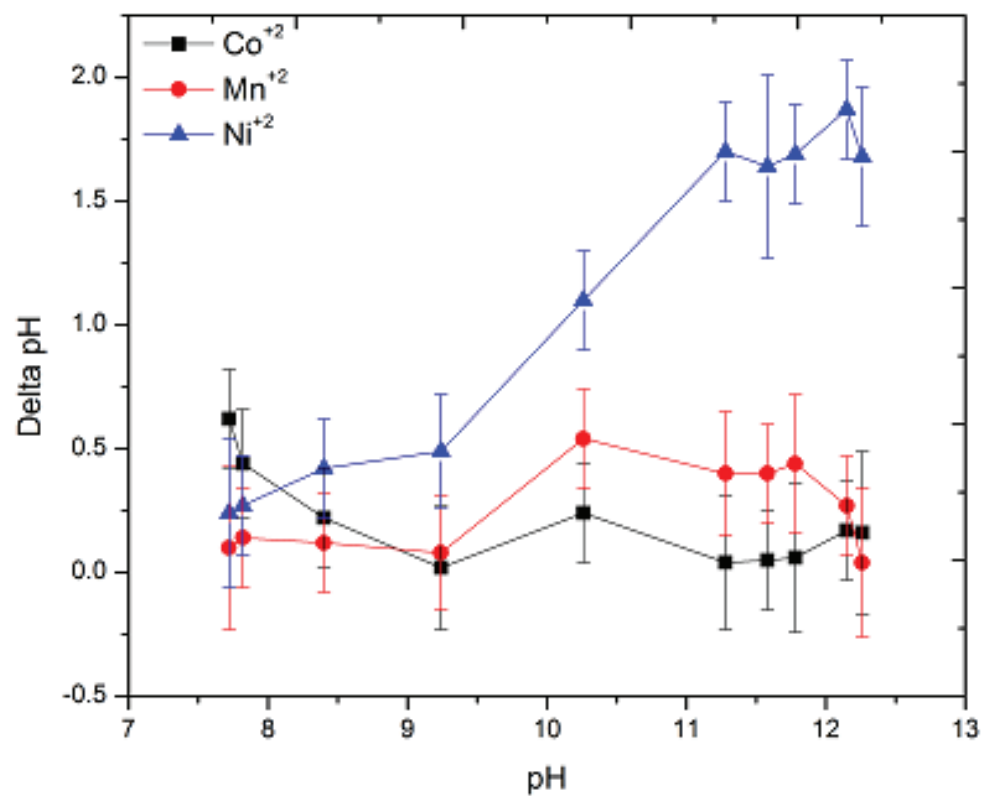

Fig. 6: $\Delta \mathrm{pH} \mathrm{v} / \mathrm{s} \mathrm{pH}$ plotted against varying concentrations of metal ions showing binding with albumin. 
decrease in the percentage transmittance. From the break in the curves, the number of moles of copper bound per mole of protein was found using the relationship $\mathrm{V}_{\mathrm{M}}=\mathrm{C}_{\mathrm{B}} / \mathrm{P}$, where, $\mathrm{P}$ is the mortality of protein and $\mathrm{C}_{\mathrm{B}}$ the mortality of copper bound at the inflexion point. The anion or cation of $\mathrm{Cu}$ interact with albumin at different fixed $\mathrm{pH}$ values was studied between 5.35 to 11.50 . At all $\mathrm{pH}$ values, the $\mathrm{pH}$ of protein was found to decrease by the addition of $\mathrm{Cu}$ of the same $\mathrm{pH}$ value. This decrease in $\mathrm{pH}$ was attributed to the preferential binding of $\mathrm{Cu}$ ions to the reactive sites of the protein. In such a case, negative $\mathrm{pH}$ ( $\mathrm{pH}$ protein- $\mathrm{pH}$ protein $+\mathrm{Cu}$ ) indicates cation binding while a positive $\mathrm{pH}(\mathrm{pH}$ protein $+\mathrm{Cu}$ - protein) is indicative of anion binding (Acharya \& Sharma 2020a).

In the present investigation, the negative $\mathrm{pH}$ values showed that $\mathrm{Cu}$ binds in the form of the cation. In low $\mathrm{pH}$ there was the perception, hence no significant changes in $\mathrm{pH}$ occurred. However, above the isoelectric point of the protein, a regular small decrease in $\mathrm{pH}$ was observed. This has been assumed to the binding of $\mathrm{Cu}$ to the protein. The amount of ligand-bound per mole of albumin $\left(10^{5} \mathrm{~g}\right)$ was calculated by the method of Scatchard \& Black (1957) from which the value of bound $\left(\mathrm{C}_{\mathrm{B}}\right)$ and free $\left(\mathrm{C}_{\mathrm{F}}\right)$ molar concentration of $\mathrm{Cu}$ was determined from the known molar concentration of albumin $\left(0.72 \times 10^{-2} \mathrm{M}\right)$. The binding was found to be sigmoidal at $\mathrm{pH}$ values 5.35, 7.50 and 9.50, since saturation is attained at higher free $\mathrm{Cu}$ concentration. The $\mathrm{Cu}_{\mathrm{M}}$ values at the saturation limit correspond to the maximum number of binding sites occupied by ligand molecules on the protein molecule. At pH 9.85 and 11.50, the $\mathrm{Cu}_{\mathrm{M}}$ rises linearly as the free ligand increased. This type of sigmoidal and linear binding isotherms is indicative of more than one class of sites and a single set of sites involved in the binding process.

The $\mathrm{Cu}$ binding by albumin is observed to be modified by $\mathrm{pH}$ and temperature. The number of binding sites decreases with rising $\mathrm{pH}$ and temperature but $\log \mathrm{K}$ remains nearly constant. The importance of constant values of $\log \mathrm{K}$, almost independent of $\mathrm{pH}$ and temperature, is that only a single primary class of sites is reacting and the appearance of their different number is therefore not responsible for decreased binding which may then be due to decreased availability of the same class of sites owing to irreversible effects in the protein structure. The free energy $\left(\Delta \mathrm{G}^{\circ}\right)$ enthalpy $\left(\Delta \mathrm{H}^{\circ}\right)$ and entropy $\left(\Delta S^{\circ}\right)$ changes of the interaction were calculated using standard methods (Barnett et al. 2013). The positive entropy $\left(\Delta \mathrm{S}^{\circ}\right)$ probably indicates that water of hydration is released both from the polar sites of protein and tetrahedral oxo copper species and that the configuration of the polypeptide is changing to a random coil as the complex formation occurs (Table-1). The higher values of entropy and enthalpy change at $\mathrm{pH} 9.85$ possibly indicates that all the above-mentioned factors may be involved at this $\mathrm{pH}$.

The experimental results showed that $\mathrm{Cu}$ interaction depends upon the $\mathrm{pH}$ of the system. The anion is first attracted to the positive centres on the protein surface by Coulombic forces and when it is sufficiently near, water molecules are removed, making the lone electron pair on nitrogen available for co-ordination with the copper atom of copper ions. The shift of the titration curve of $\mathrm{Cu}$-albumin complex towards higher $\mathrm{pH}$ may perhaps be in line with the type of binding because $\mathrm{H}^{+}$reacts with $\mathrm{CuSO}_{4}$ ion which in turn is removed as a water molecule on reacting with albumin. In the lower $\mathrm{pH}$ range, the complex may be formed through coordination and hydrogen bonding with protonated nitrogen and undissociated carboxyl groups of albumins. However, in the higher $\mathrm{pH}$ range, the decreased binding can be explained based on the following facts.

1. The number of $-\mathrm{OH}$ groups in the polyacid decreased and as a result, the number of linkages also progressively decreased with the decreasing metal oxide.

2. Protein becomes either swollen or unfolded when the net negative charge increases. As the $\mathrm{pH}$ increases and the charge becomes more negative, electrostatic repulsion causes an even greater opening of the protein until a

Table 1: Binding constants of albumin - Cu (II) system by pH displacement method.

\begin{tabular}{|c|c|c|c|c|c|}
\hline $\mathrm{pH}$ & $\mathrm{n}$ & $\log \mathrm{k}$ & $\begin{array}{l}\Delta \mathrm{G}^{0} \\
(\mathrm{Kcal} / \mathrm{mole})\end{array}$ & $\begin{array}{l}\Delta S^{0} \\
\left(\mathrm{cal} \mathrm{mole}^{-1} \mathrm{deg}^{-1}\right)\end{array}$ & $\begin{array}{l}\Delta \mathrm{H}^{0} \\
(\mathrm{Kcal} / \mathrm{mole})\end{array}$ \\
\hline \multicolumn{6}{|l|}{$25^{\circ} \mathrm{C}$} \\
\hline 5.34 & 11 & 3.95 & -5415 & +5.0 & \\
\hline 7.50 & 9 & 3.78 & -5.182 & - & \\
\hline 9.50 & 8 & 3.61 & -4.949 & - & \\
\hline 9.85 & 7 & 3.60 & -4.835 & +14.0 & \\
\hline 11.50 & 3 & 3.60 & -4.835 & +8.6 & \\
\hline \multicolumn{6}{|l|}{$40^{\circ} \mathrm{C}$} \\
\hline 5.34 & 9 & 3.81 & -5.486 & +4.7 & +4.000 \\
\hline 9.85 & 6 & 3.58 & -5.155 & +14.6 & -0.572 \\
\hline 11.50 & 2 & 3.52 & -5.068 & +6.0 & -2.266 \\
\hline
\end{tabular}


maximum is reached, as predicted by the diminished $\mathrm{Cu}$ binding results.

3. The progressive deprotonation of the nitrogen atoms would result in a smaller number of positive loci, therefore, resulting in a decreased binding.

4. Protein becomes swollen or unfolded when the net negative charge increases. As the $\mathrm{pH}$ increases and the charge becomes more negative, and the electrostatic repulsion causes an even greater opening up of the protein until a maximum is reached as predicted by the diminished anion binding results.

The polarographic behaviour of mercuric chloride ion is interesting because the polarograms in lower potential range possess a small maximum. The addition of even a smaller amount of albumin suppressed the maxima as well as decreased the current height. The abstraction of maxima from polarograms by the presence of albumin is a direct indication of the combination between albumin and mercury $(\mathrm{Hg})$ ions. Furthermore, the addition of more and more amounts of albumin caused a progressive decrease in the current height. This reduction in current height may be due to successive removal of $\mathrm{Hg}$ ions from the systemic increasing amounts of albumin which react with more and more $\mathrm{Hg}$, which is a cause of the depression in the current height of axometal ion.

The polarographic data viz. Hgm and Hgf can be analysed in many ways. For qualitative representation, these are plotted in the form of logarithmic plots i.e. Hgm is plotted against log free equilibrium concentration of $\mathrm{Hg}$ ions. These isotherms at $25^{\circ} \mathrm{C}$ indicate the extent of binding increases progressively as the $\log$ free concentration rises and ultimately assumes $\mathrm{S}$-shape. This indicates the saturation of binding sites in both cases i.e. at and 0.5 percent albumin concentrations. The binding data were also explained in terms by a protein, the first bound ion tends to reduce the affinity of the protein for the second oncoming ion because of the electrostatic factor in protein the binding constants $\mathrm{n}$ (binging sites) and $\mathrm{K}$ (association constant) may be calculated by equation (1).

Where, $\mathrm{K}$ is the average apparent association constant for the binding at each site and $\mathrm{n}$ is the average maximum number of binding sites on protein with the same association constant $\mathrm{K}$. If all the protein sites are equivalent and independent, a plot of $\mathrm{Hgm} / \mathrm{HgF}$ as a function of $\mathrm{Hgm}$ would reveal a linear nature such that the intercept on the $\mathrm{Hgm} / \mathrm{HgF}$ axis is $\mathrm{Knx}$, as $\mathrm{Hgm}$ approaches zero as a limit. And the intercept on the $\mathrm{Hg}$ $\mathrm{m}$ axis is $\mathrm{n}$ as $\mathrm{Hgm} / \mathrm{HgF}$ approaches zero as a limit deviation from linearity may occur when linking takes place at more than one set of sites with different values of the association constant (Fig 7). The contribution of the electrostatic factors may also produce deviation from the linear nature of the plot. A linear relationship is found to exist between $\mathrm{Hgm} /$ $\mathrm{HgF}$ and $\mathrm{Hgm}$ at both the albumin concentrations, which is an indication of the involvement of only one class of sites that are equivalent and independent (Sendzik et al. 2017). A slight curvature in the lower limit of Scatchard plot may be due to change in the structure of interacting mercury species as its nature of concentration depended on the binding sites for 0.5 and 0.2 percent albumin were found to be 33 and 50 , respectively. While the association constant for the single site being 303 and 140 respectively, corresponding to the

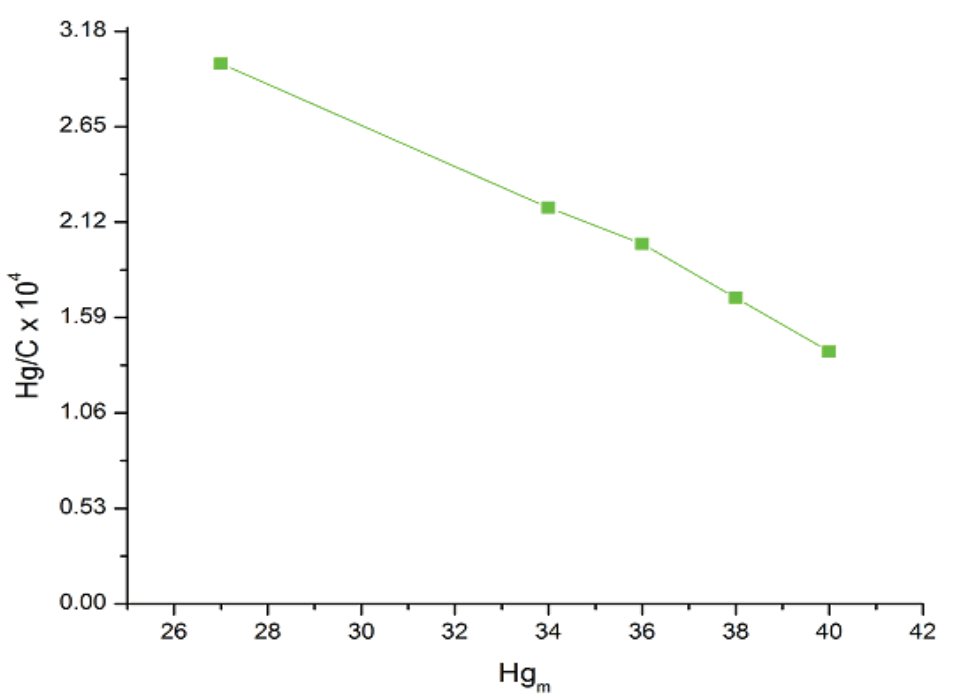

Fig. 7: A plot between $\mathrm{Hgm} v / \mathrm{s} \mathrm{Hgm} / \mathrm{C} \times 10^{4}$ of albumin with $\mathrm{Hg}$ at $\mathrm{pH}=7.50, \mathrm{~T}=30^{\circ} \mathrm{C}, \mu=0.15$. 
$\log \mathrm{K}$ value of 2.481 and 2.146 respectively. The free energy changes of the combining sites are found to be only 4.6458 and $4.1852 \mathrm{Kcal} / \mathrm{mole}$.

The difference in the number of binding sites (n) association constant $\mathrm{K}(\log )$ and free energy at two-protein concentration revealed that the protein molecule possesses different structural organizations in its dilute and concentrated solution. This is a reflection of the availability of different ligand binding sites is less than the total of 53 cationic groups on albumin molecule, but the increased $\mathrm{Hgm}$ at $\mathrm{pH} 9.5$ than at 7.50 creates some ambiguity of the mercury ions binding sites. Furthermore, at $\mathrm{pH} 7.50$ the 15 imidazolium would be unprotonated i.e. out of the 53 cationic groups only 38 groups remained protonated. On the other hand, at $\mathrm{pH} 9.50$ both imidazolium and ammonium groups get deprotonated and thus only 24 albumin groups remain protonated (Arora et al. 1983b). As $\mathrm{Hg}$ binding is found more at $\mathrm{pH} 9.50$ than at 7.50 , hence the ionized carboxyl and phenolic groups have participated in interaction with oxo-mercury $(\mathrm{Hg})$ albumin linkage. The albumin constrains carboxyl group and mercury is known to bind with phenolic oxygens of the metal-binding sites of human serum. Thus, in the case of albumin, the anionic carboxyl and phenolic groups are bound to oxo-mercury rather than the nitrogen-containing groups.

\section{CONCLUSION}

Based on the results of the experiments which were conducted to examine the interaction between anionic surfactant/metal ions and protein by measuring the various parameters of the solutions, it is concluded that the interaction of surfactant and protein gives an idea of fundamental understanding of the structure of surfactant-protein complex and the practical applications in every field.

\section{ACKNOWLEDGMENTS}

The authors pay their sincere gratitude to UGC for financial assistance as TRF and Principal, Govt. College Kota and S.P.C. Govt. College Ajmer, Rajasthan (India) for providing necessary research facilities to accomplish this study.

\section{REFERENCES}

Acharya, S. and Sharma, A.K. 2018a. Interaction Studies of Metals and Surfactant with Protein. ISBN 978-613-8-38751-0, LAP LAMBERT Academic Publisher Germany.

Acharya, S. and Sharma, A.K. 2018b. Binding studies of metal ions and dyes with biopolymers "ISBN 978-613-8-38659-9" LAP LAMBERT Academic Publisher Germany.

Acharya, S. and Sharma, A.K. 2018d. The thermodynamic and pH metric studies on the binding of $\mathrm{Hg}+2$ and $\mathrm{Mo}+2$ with RNA by polarographic and spectrometric techniques Current Phys. Chem., 8(3): 186-193.
Acharya, S. and Sharma, A.K. 2019a. The thermodynamic and binding studies of $\mathrm{Hg}^{+2}$ ions with egg protein by polarographic and $\mathrm{pH}$ metric techniques. Z. Phy. Chem., 233(8): 1073-1090

Acharya, S. and Sharma, A.K. 2019b. The thermodynamic and pH metric binding studies of $\mathrm{Cu}^{+2}$ ions with egg protein by Spectrometric and diffusion current techniques. Z. Phy. Chem. (In Press).

Acharya, S. and Sharma, A.K. 2019c. the binding and viscometric studies of $\mathrm{Ni}^{+2}, \mathrm{Co}^{+2}$ and $\mathrm{Mn}^{+2}$ ions with protein by spectrometric and $\mathrm{pH}$ metric techniques. Current Phys. Chem., 9(2): 151-162.

Acharya, S. and Sharma, A.K. 2020a. spectrometric, thermodynamic, pH metric and viscometric studies on the binding of TEALS as surfactant with albumin as biopolymer. Current Phys. Chem., 10(1): 47-64.

Arora, J.P.S., Singh, R.P., Soam, S., Singh, S.P. and Kumar, R. 1983a. Binding of oxovanadium $(\mathrm{V})$ anion to bovine serum albumin, human serum albumin and bovine pancreatic trypsin. Bioelectrochem, Bioererg., 10: 289-300.

Arora, J.P.S., Singh, R.P., Soam, S., Singh, S.P. and Kumar, R. 1983b. The interaction between bovine serum albumin and the molybdate ions. Bioelectrochem. Bioenerg., 10: 441-450.

Barnett, J. P., Blindauer, C. A., Kassaar, O., Khazaipoul, S., Martin, E. M., Sadler, P. J. and Stewart, A.J. 2013. Allosteric Modulation of zinc speciation by fatty acids. Biochimica et Biophysica Acta (BBA) - General Subjects, 1830(12): 5456-5464.

Drabovich, A.P., Pavlou, M.P., Batruch, I. and Diamandis, E.P. 2013. Proteomic and mass spectrometry technologies for biomarker discovery. In: Proteomic and metabolomic approaches to biomarker discovery, Issaq, H.J., and Veenstra, T.D., Eds. Elsevier: London, UK, p. 18-39.

Dudev, T., Dudev, M. and Lim, C. 2003. First-second shell interactions in metal binding sites in proteins: A PDB survey and DFT/CDM calculations. J. Am. Chem. Soc., 125: 3168-3180.

Espósito, B. P. and Najjar, R. 2002. Interactions of antitumoral platinum-group metallodrugs with albumin. Coord. Chem. Rev., 232(1): 137-149.

Frassinetti, S., Bronzetti, G. L., Caltavuturo, L., Cini, M. and Croce, C. D. 2006. The role of zinc in life: A review. JEP(T), 25(3): 597-610.

Harding, M.M. 1999. The geometry of metal-ligand interactions relevant to proteins. Acta Crystallogr. D. Biol. Crystallogr., 55: 1432-1443.

Harding, M.M. 2000. The geometry of metal-ligand interactions relevant to proteins. II. Angles at the metal atom, additional weak metal-donor interactions. Acta Crystallogr. D. Biol. Crystallogr., 56: 857-867.

Harding, M.M. 2004. The architecture of metal coordination groups in proteins. Acta Crystallogr. D. Biol. Crystallogr., 60: 849-859.

Harris, W.R. 1984. Carrano C.J. Binding of vanadate to human serum transferrin. J. Inorg. Biochem., 22: 201-218.

Hawker, R.R., Haines, R.S. and Harper, J.B. 2018. Predicting solvent effects in ionic liquids: Extension of a nucleophilic aromatic substitution reaction on a benzene to a pyridine. J. Phys. Org. Chem., 31: e3730.

Joshi, T. 2018. Interaction of bile salts with Cetylpyridinium chloride: Surface tension and viscosity measurements. Curr. Phys. Chem., 8: 86-94.

Keilin, D. and Mann, T. 1940. Carbonic anhydrase. purification and nature of the enzyme. Biochem. J., 34(8-9): 1163-1176.

Kumar, D. and Rub, M. A. 2018. Interaction of ninhydrin with chromium-glycylglycine complex in the presence of dimeric gemini surfactants. J. Mol. Liquids, 250: 329-334.

Kumar, D., Azum, N., Rub, M. A. and Asiri, A. 2018. Aggregation behaviour of sodium salt of ibuprofen with conventional and gemini surfactant. J. Mol. Liquids, 262: 86-96.

Lu, J., Stewart, A. J., Sadler, P. J., Pinheiro, T. J. T. and Blindauer, C. A. 2008. Albumin as a zinc carrier: properties of its high-affinity zinc-binding site. Biochem. Soc. Trans., 36(6): 1317-1321.

Lyons, T.J. and Eide D.J. 2006. Transport and storage of metal ions in biology. In: Biological Inorganic Chemistry: Structure and Reactivity (ed. Bertini, I., Gray, H., Stiefel, E. and Valentine, J.S.), pp. 57-78. 
Scatchard, G., Coleman, J.S. and Shen, A.L. 1957. Physical chemistry of protein solutions. vii. The binding of some small anions to serum albumin. J. Am. Chem., Soc., 79: 12-20.

Sendzik, M., Pushie, M. J., Stefaniak, E. and Haas, K.L. 2017. The structure and affinity of $\mathrm{Cu}(\mathrm{i})$ bound to human serum albumin. Inorg. Chem., 56(24): 15057-15065.

Sharma, A.K. Acharya, S. 2018c. The interaction and thermodynamic studies on the binding of congo red dye with collagen protein by polarographic and equilibrium dialysis techniques. Z. Phys. Chem., 233(5), 691-701.

Sharma, A.K. and Acharya, S. 2018. The Interaction and thermodynamic studies on the binding of congo red dye with collagen protein by polarographic and equilibrium dialysis techniques. Z. Phys. Chem., 233(5): 691-701.

Stern, B. R., Solioz, M., Krewski, D., Aggett, P., Aw, T.C., Baker, S., Crump, K., Dourson, M., Haber, L., Hertzberg, R., Keen, C., Meek,
B., Rudenko, L., Schoeny, R., Slob, W. and Starr, T. 2007. Copper and human health: biochemistry, genetics, and strategies for modeling dose-response relationships. J. Toxicol. Environ. Health, Part B, 10(3): 157-222.

Stewart, A. J., Blindauer, C. A., Berezenko, S., Sleep, D. and Sadler, P.J. 2003. Interdomain zinc site on human albumin. PNAS, 100(7): 37013706.

Tank, P., Sharma, R. and Sharma, A.K. 2018. Micellar features and various interactions of copper soap complexes derived from edible mustard oil in benzene at 303.15 K. Curr. Phys. Chem., 8: 46-57.

Van, Q.N. 2013. Current NMR strategies for biomarker discovery. In: Proteomic and Metabolomic Approaches to Biomarker Discovery, Issaq, H.J., and Veenstra, T.D., Eds. Elsevier: London, UK, pp. 88-119.

Zheng, H., Chruszcz, M., Lasota, P., Lebioda L. and Minor W. 2008. Data mining of metal ion environments present in protein structures. J. Inorg. Biochem., 102: 1765-1776. 